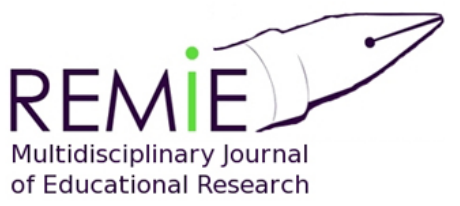

Hipatia Press

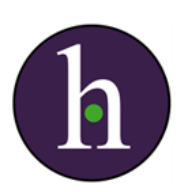

Instructions for authors, subscriptions and further details:

http://remie.hipatiapress.com

\title{
Adinkra Mathematics: A Study of Ethnocomputing in Ghana
}

William Babbitt ${ }^{1}$, Michael Lachney ${ }^{1}$, Enoch Bulley ${ }^{2}$, Ron Eglash ${ }^{1}$

1) Rensselaer Polytechnic Institute. United States

2) Ayeduase Junior High School. Ghana

Date of publication: June $15^{\text {th }}, 2015$

Edition period: June 2015 - October 2015

To cite this article: Babbitt, W., Lachney, M., Bulley, E., \& Eglash, R. (2015). Adinkra Mathematics: A study of ethnocomputing in Ghana. Multidisciplinary Journal of Educational Research, 5(2), 110-135.

doi:10.17583/remie.2015.1399

To link this article: http://doi.org/10.17583/remie.2015.1399

\section{PLEASE SCROLL DOWN FOR ARTICLE}

The terms and conditions of use are related to the Open Journal System and to Creative Commons Attribution License (CCAL). 


\section{Adinkra Mathematics: A study of Ethnocomputing in Ghana ${ }^{1}$}

William Babbitt

RPI

Enoch Bulley

Ayeduase Jr High School
Michael Lachney

RPI

Ron Eglash

$R P I$

\section{Abstract}

This paper details the development and evaluation of software that allows middle school students to explore the mathematical aspects of Ghanaian Adinkra symbols. We tested the effectiveness of this simulation in a Ghanaian junior high school by conducting a randomized quasi-experiment. We begin this paper by framing culturally responsive math education within the interventionist tradition of ethnomathematics. We draw this tradition together with an empirical exploration of the mathematics embedded in Adinkra symbols. We follow this with a methodological explanation for how we translated the mathematical significance of Adinkra into the design of our software, "Culturally Situated Design Tools." Finally, we describe the quasi-experimental evaluation of the software using a randomized assignment of students in control and intervention groups in Ghana. We found statistically significant improvement for students using the culture-based software in comparison to similar software with no cultural content.

Keywords: indigenous knowledge, ethnomathematics, Ghana, culturally responsive education, Adinkra symbols 


\section{Matemáticas Adinkra: Un Estudio de Etnocomputación en Ghana ${ }^{1}$}

William Babbitt

$R P I$

Enoch Bulley

Ayeduase Jr High School
Michael Lachney

$R P I$

Ron Eglash

$R P I$

\section{Resumen}

Este artículo detalla el desarrollo y la evaluación de un software que permite a estudiantes de secundaria explorar los aspectos matemáticos de los símbolos Adinkra de Ghana. Se puso a prueba su eficacia en una escuela secundaria de Ghana mediante la realización de un casi-experimento aleatorizado. El artículo comienza enmarcando la educación matemática culturalmente responsable en la tradición intervencionista de las etnomatemáticas. Se combina esta tradición con una exploración empírica de las matemáticas presentes en los símbolos Adinkra. A continuación se explica cómo traducir el significado matemático de Adinkra en el diseño del software "Culturally Situated Design Tools". Por último, se describe la evaluación cuasi-experimental del software usando una asignación aleatoria de estudiantes en grupos de control y grupos de intervención en Ghana. Se encuentra una mejoría estadísticamente significativa en los estudiantes que utilizan el software basado en la cultura, en comparación con un software similar sin contenido cultural.

Palabras clave: conocimiento indígena, etnomatemática, Ghana, educación culturalmente sensible, símbolos Adinkra 


\section{Babbitt, Lachney, Bulley \& Eglash-Adinkra Mathematics}

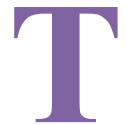

his paper describes our research on the development and evaluation of computer simulations for culture-based math education in Ghana. These simulations belong to a suite of web applets, "Culturally Situated Design Tools" (CSDTs), which bring together ethnomathematics research with the "sandbox" approach of open-ended design software (Eglash et al., 2006). The CSDT we focus on for this project is "Adinkra Computing," which allows students to simulate the geometric forms and algorithmic composition of a textile stamping tradition in Ghana. We will briefly review the research on ethnomathematics in culturally responsive education. We then describe the empirical foundation for Adinkra Computing, the design of the software, and the testing of the software in a quasi-experimental evaluation that compares the mathematical performance of control and intervention groups of Ghanaian junior high school students.

A 2004 report by Ghana's Ministry of Education concluded that when compared internationally, Ghanaian junior high school students' math scores lag significantly behind other nations in algebra, geometry, and measurement (Anamuah-Mensah, Mereku \& Asabere-Ameyaw, 2004). There are likely multiple causes for this lower performance. Research suggests that underpaid teachers and the lack of access to basic educational materials place students at a disadvantage (Osei, 2006). Economic issues such as currency depreciation and price inflation heighten these factors. While addressing these structural issues is beyond the reach of pedagogy, there are other factors, which can ameliorate these effects within the classroom. Ghanaians may be poor in monetary wealth, but they are rich in cultural capital. Thus there have been recent attempts by parents, teachers, administrators, and policy makers to improve Ghanaian education through the use of culturally relevant local resources (Dei, 2004). We hypothesize that ethnomathematics (Ascher, 1994; Ascher \& D'Ambrosio, 1994) and its sister discipline of ethnocomputing (Eglash et al. 2006) are areas of research that can help Ghanaian educators in their efforts to utilize culturally responsive education as a means to improve student mathematics achievement. 


\section{Research on Ethnomathematics as Intervention in Education}

The ethnomathematics literature has no lack of visionary statements on what its advantages might be. In some cases, the motivation comes from the concept of "cultural relevance" to a specific population. Jama (1999) for example draws out normative connections between indigenous mathematics and science of the Somali culture in the Horn of Africa region and local school curriculum. He suggests that ethnomathematics can be used as a "special language" to help students see themselves as historical and political actors through deep engagement in their own cultures' mathematical heritage. In other cases, ethnomathematics is framed more broadly as a way to challenge curricular Eurocentrism (Anderson, 1990; Frankenstein \& Powell, 1994; Gerdes, 1985). The latter stresses the use of ethnomathematics not in terms of a specialized fit to a particular population, but rather as a way to enable students' understanding of math as an empowering tool in the repertoire of humanitarian practices. As a research program present within and outside school walls, ethnomathematics challenges classic notions of math education while also revealing power dynamics about who is represented and hidden within curricula.

Zaslavsky (1994) describes her early ethnomathematics research as motivated by the fact that African mathematics did not appear in US library catalogs, nor did she find any information on the topic when she contacted the Secretariat in Ghana. This is not a casual happenstance. Western "exceptionalism" has a pervasive hold on its math and science as the only accurate way to explain reality (Elliott, 2009; Harding, 2008). This has profound influence on non-Western education. Indigenous math and science continues to be marginalized in Ghanaian and other African curricula (Ahia \& Fredua-Kwarteng, 2012), despite persuasive arguments that its inclusion may help with problems of enrollment, engagement, and performance (Ezeife, 2003).

In the US context, these arguments have found empirical support in the work of the Alaskan Native Knowledge Network. Lipka et al. (2005) for example developed a set of culture-based lessons for native Alaskan students, which combine discovery or inquiry learning pedagogy with contexts that emphasize native Alaskan traditional knowledge. Their work 


\section{Babbitt, Lachney, Bulley \& Eglash-Adinkra Mathematics}

shows statistically significant improvement in pre/post test scores for the intervention group in comparison to their control group (Kisker et al., 2012). Similar quantitative evidence for the efficacy of this approach has been used among students of many racial backgrounds--not only Native American but African American and Latino as well. In some of this research, the pedagogy is known as "ethnocomputing": the use of simulations to allow students to explore indigenous and vernacular knowledge spanning both mathematical topics as well as computational thinking (Eglash \& Bennett, 2009). For example, in one study, African fractals were introduced in an ethnically diverse high school computing class in New York City: this intervention group showed statistically significant improvement on pre/post comparisons relative to a control group which received similar instruction without any cultural connections (Eglash et al., 2011). Despite this evidence for efficacy, there has been little serious adoption in most curricula (Khan, 2011); even when cultural connections are introduced, the overwhelming tendency is to only superficially represent indigenous knowledge (D'Ambrosio, 2010a).

While the "culture" side of ethnomathematics can vary widely-including topics from vernacular culture such as graffiti, working class skills such as carpet laying, and even investigations of cultural influences in professional mathematics--indigenous math plays a special role, as it directly contradicts the pernicious myths of genetic determinism. When students are convinced that there is a "math gene" enjoyed by Asian and white students but denied to students of African or other indigenous heritage, it becomes a self-fulfilling prophecy (Steele et al., 2002). Indigenous ethnomath or ethnocomputing directly contradicts that myth. Similarly, the colonial legacy introduces a myth of cultural determinism: Fordham (1991) and Ogbu (1998) document the ways in which African American students perceive a forced choice between black identity and high scholastic achievement. Fryer and Torelli (2010) found statistical evidence supporting the contention that high-achieving African American students are often accused of "acting white" by their peers. This means that culturally responsive educational interventions should always be conscious of the difficulties some students face when reconciling their own identities 
with those identities offered-up by teachers and curricula in mathematics and computer classrooms (Cobb \& Hodge, 2002).

Finally, we note that there is a mimetic resonance between these historical modes of epistemological domination and pedagogical styles of authoritarian learning. Just as rote memorization is often justified to satisfy the ends of testing at the expense of learning that students find meaningful, lasting colonial legacies form a "neocolonial" context that justifies a putative universal form of knowledge at the expense of the flourishing of cultural traditions. Thus, the potential for indigenous knowledge to have meaningful influence on student performance is not merely a matter of test scores, since institutional bodies that aim to meet the demands of a workforce employed by global financial forces, environmentally destructive industries, and increasingly deadly militaries all directly or indirectly create the content for those standardized tests. It is no surprise that indigenous knowledge systems appear to be ill suited for the mathematical and computational knowledge base of these enterprises. Nonetheless, it is our hypothesis--supported by statistically significant empirical studies--that schools can have their cake and eat it too: that incorporating indigenous knowledge systems into a math and computing curriculum can both raise student scores on tests that are influenced by these institutions, and simultaneously help to impart the cultural, ecological and ethical knowledge (Eglash \& Garvey, 2014) that will offer solutions to these harmful global forces.

A significant amount of research demonstrates that for education to have lasting impacts on students' knowledge, they must be able to interact emotionally and critically with content that is culturally relevant to their communities and identities (Gutstein, 2006; Roth \& Barton, 2004; Nasir, 2002). Here we offer evidence, based on our Ghanaian case study, that research in ethnocomputing offers the opportunity to design such curricula that better motivates students' academic engagement. Simultaneously, we suggest that the inclusion of indigenous knowledge in classroom activities can offer a way to support indigenous traditions that foster sustainable relations between the natural and social worlds. We see this work as part of larger ethnomathematics and ethnocomputing projects that fight against political and epistemological inequalities through, "restoring cultural 
116 Babbitt, Lachney, Bulley \& Eglash - Adinkra Mathematics

dignity and offer[ing] the intellectual tools for the exercise of citizenship" (D’Ambrosio, 2010b).

\section{Ghanaian Adinkra Symbols}

Adinkra symbols can be primarily observed today in Ghanaian textiles. The Akan peoples of Ghana adopted Adinkra textiles around the year 1800, yet the origins of the craft remain uncertain (Willis, 1998). Many of their geometric forms exist in older archaeological artifacts, across a wider geographic range. In the case of the textiles, these were originally used in the funerary arts with each symbol communicating a particular idea to the departed loved one. Contemporary uses of Adinkra symbols have expanded well beyond the funerary arts. Traditional Adinkra artisans in Ntonso, Ghana still carve symbols from the calabash gourd, make their own ink, and stamp various types and styles of cloth; primarily for tourists that visit their shops. A drive through nearby Kumasi reveals Adinkra symbols on garden walls, the columns of Internet cafes, and molded into the backs of plastic chairs. In the 21st century, Adinkra has become a global phenomenon. In the United States, Adinkra symbols adorn everything from t-shirts and jewelry to braiding salons.

During 2010-2014 we engaged in ongoing ethnographic research on the mathematical and computational significance of Ghanaian Adinkra symbols. This research included teaching interventions in Ghanaian junior high schools. The foundation of this work is based on Eglash's (1999) research that documents Ghanaian pre-colonial knowledge of logarithmic curves in symbolic representations of organic growth. Western mathematicians have long recognized logarithmic curves as a defining characteristic of organic growth. Darcy Thompson's 1917 classic, On Growth and Form, was one of the first works to provide a formal analysis. Today specific examples such as the Fibonacci sequence in plant spirals have become a math textbook staple, while more complex theories for the ubiquity of power laws in biological morphogenesis are the subject of significant research programs (eg West, Brown, \& Enquist, 1997). While we do not want to attribute understandings that are not actually present, there is solid evidence that pre-colonial Ghanaian designers consciously 
employed logarithmic scaling--in particular the log spiral--as a visual model for the underlying geometric forms common to living organisms. Adinkra symbols do not just mimic organic growth; they are a means of representing a hybrid knowledge form at the intersections of biological, mathematical, and social concepts.

In the pre-colonial Ghanaian context, the logarithmic curves found in Adinkra designs are consistently associated with biological structures. Examples (Figure 1-3) include the ram's horn, chicken's foot, and curve of a long-necked bird. Each symbol represents a colloquial saying connected to cultural and ethical values. For example, Dwennimen, the ram's horns, is associated with the saying "it is the heart, and not the horns that leads a ram to bully." In a science classroom this saying can be interpreted by teachers and students through a biological lens that strongly relates natural and social worlds: it is not genetics (the horns you were born with), but rather your efforts (from your heart) that matter.

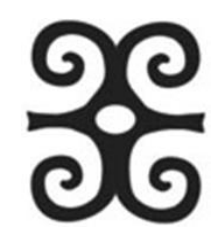

Figure 1. Dwennimen: ram's horns.

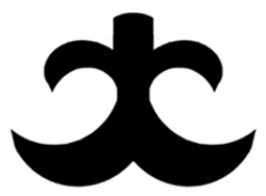

Figure 2. Akoko nan: chicken's foot. 


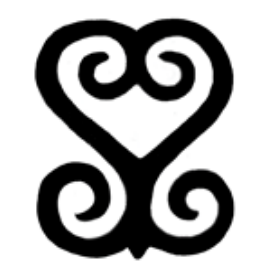

Figure 3. Sankofa: bird's neck.

Figure 4 shows a fourth Adinkra symbol that uses log curves, "Gye Nyame". It has a stronger mathematical significance: while the other symbols show log curves associated with a particular biological structure, the Gye Nyame symbol is a generalization of log curves as emblematic of life in general. The saying associated with this symbol is "no one except for God". The bumps down the center represent the knuckles of a fist; a symbol of power. At each end there is a logarithmic curve, the curves of life (Cook, 1979). Thus, the aphorism becomes less cryptic: "no one except God holds the power of life".

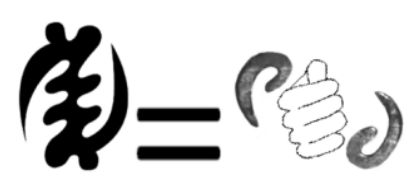

Figure 4. Gye Nyame similarities to the knuckles on a fist (Eglash, 1999).

This syncretic mathematical/cultural/biological significance of logarithmic curves in Adinkra forms the basis for our educational interventions. The logarithmic curves of Adinkra not only vary across symbols but also in different variations of the same symbol, creating a rich body of geometric forms suitable for discovery or inquiry learning. Are certain symbol curves quantitatively similar to their biological sources of inspiration? How does mathematics model the distinctions our eyes and visual intuition tend to make? Does the variation that different artists give to the same symbol indicate differences in skill, media, traditions, or other affiliations? Because the 2D form requires a more complicated description, we began by considering only the 1D "edge" of these shapes, modeling 
them as the arc of a logarithmic spiral. Thus we could focus on two parameters: the angle "sweep" of the log spiral arc, and a constant C that determines the overall shape (from the equation in polar coordinates: Radius = CTheta). We referred to the constant "C" as the amount of "coilness" (either tightly or loosely) in the curve, in our work with the Ghanaian junior high school students. For example, consider the Adinkra symbol Sankofa, which means, "you can always return to your roots" (hence the bird looking backwards). In Figure 5, we can see that the logarithmic spiral makes up the curve of the Sankofa's neck. Variations to the design of Sankofa result from the changes in the exponential parameter or coilness of the neck. Figure 6 has a smaller exponential parameter than Figure 7, which results in the more closed, tightly coiled spiral. Figure 7 has a larger exponential parameter resulting in a more open, loosely coiled spiral. As we describe in the next section, this mathematical insight was designed into the log spiral "block" of Adinkra Computing CSnap software as the value "C".

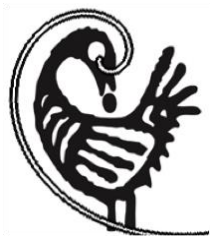

Figure 5. Logarithmic spiral overlaid on top of Sankofa.

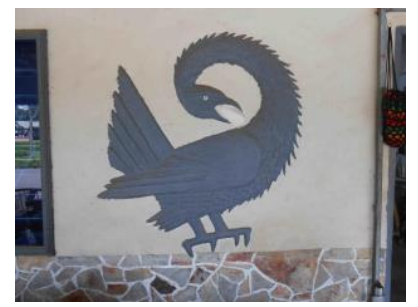

Figure 6. Sankofa with tight curvature. 


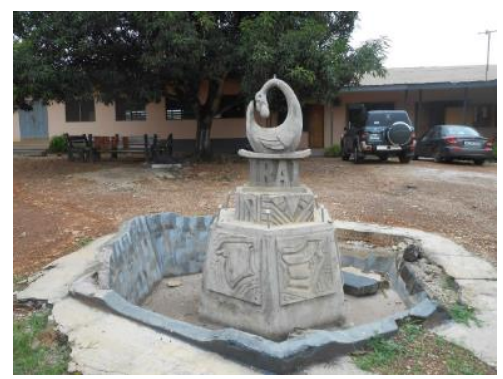

Figure 7. Sankofa with loose curvature.

Adding the mathematical significance of Gye Nyame, Sankofa, and other Adinkra symbols to Ghanaian educational contexts could create a valuable alternative to dominant curricular models, which simultaneously claim to be non-cultural abstract universals, and at the same time make clearly Western references (Pythagorean Theorem, Archimedean spiral, etc.). Paulo Freire (2000) argues that the decontextualization of education from learners' concrete experiences is alienating. While the Ghanaian national curriculum has made an admirable effort to include Adinkra and other local cultural resources in its humanities curriculum, Freire's critique is still applicable in the case of math and science in Ghanaian schools.

The study of Ghanaian culture could be incorporated in schools starting in the lower primary levels where students are taught how to identify and draw geometric shapes. Pupils could draw some of the easiest traditional symbols, such as the Akoma (heart shape), in addition to other basic shapes already in the curriculum. This would make it easy for students to view their heritage as having contemporary significance rather than merely a holdover from earlier times. However, this cultural background is more often taught as part of the Ghanaian language subject in junior high schools; there is no connection to the study of math, science and technology. Despite the clear presence of mathematical concepts such as geometric transformations, the Cartesian plane and basic computations employed by artisans in the making of the Adinkra symbols, none of these resources are fused into the teaching of math and science in the classroom. Most of the 
examples and illustrations given to students are purely abstract theories, with any concrete illustrations taken from the most generic examples.

One issue that challenges the fusion of culture into math, science and technology education is the fact that each of the ten regions in Ghana has differences in their cultural practices and values. In effect, there are different contents for the Ghanaian language curriculum and syllabus depending on the region a student finds him or herself. For instance, while a student in the Northern Region may be learning about mud architecture, those in Upper West region might be learning about the Xylophone as part of their cultural heritage. This is another reason why Adinkra is particularly appropriate; the symbols have taken on a status as part of the Ghana national culture shared by all regions, and even internationally as symbolic of African heritage.

\section{Culturally Situated Design Tools}

The suite of Culturally Situated Design Tools ${ }^{2}$ offers a variety of user interfaces and cultural contexts that aim to help teachers and students make deep connections between math, science, computing, and social knowledge. The Adinkra Computing user interface shown in Figure 8 is a programmable CSDT that allows users to configure blocks of code that script various mathematical operations. The design of each CSDT begins with fieldwork. In the case of Adinkra Computing, we interviewed and observed the practices of Adinkra ink makers, carvers, stampers, and other cultural experts. This data helped us to understand the underlying mathematical aspects of Adinkra from an indigenous perspective, rather than simply impose the meaning from an outsider's view. ${ }^{3}$

During the design process, software developers who aim to translate the embedded math of Adinkra artisans into the code, graphical user interface, and user-experience, work to reinterpret this data. Some compromise is always necessary, as the ways in which artistic practices embody mathematical or computational thinking may not be optimal for either student use or pedagogical clarity; the final interface is an attempt to find 


\section{Babbitt, Lachney, Bulley \& Eglash-Adinkra Mathematics}

the "sweet spot" in which all three goals--cultural fidelity, student learning and curricular content--offer mutual support.

In Figure 8 you can see a simulation for the Akoma Adinkra symbol, which stands for "love, good will, and patience" (Willis, 1998). The user interface shows the programming building blocks in blue (left most column), the scripting panel (middle column), and the output window on the right. The user (student) designs an Adinkra symbol by dragging code blocks (i.e. black-boxed rules and functions) from the leftmost panel into the middle-scripting window. Students typically arrange the code blocks using some combination of planning and trial and error experimentation, checking each time the script is run to see if the results are close to the desired design.

For those curious about the internal operation of the code, a good analogy might be a script for a play in which each actor reads his or her part. When the user presses the green "play" button, she puts the applet into the running state, which triggers an event queue to cycle through all of the system objects (the actors) in the queue. This updates the system values for all of the object attributes affected by the code blocks (the script) that have been added to the event. The play button is one of these events, but a code block can send out triggers to other code blocks. The updates to values and any other changes to system parameters result in the alteration of the behaviors (typically graphical) that appear in the output portion of the user interface.

Unlike similar programs such as Scratch, these code blocks offer operations specific to many of the Adinkra designs, and their execution is as close as possible to the original Adinkra artisan practices. For example, at the end of the script in Figure 8, two log spiral blocks make up the curves of Akoma. The "costume" worn by the object leaving these curved paths is a photo of the hand of master carver Paul Boakye, holding his carving knife. We took pains to use an algorithm that always orients the blade along the tangent to the curve; thus adding both cultural accuracy and mathematical learning content. 


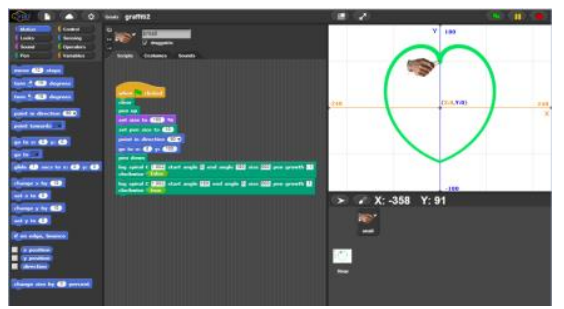

Figure 8. CSnap interface with the Akoma script.

When the system encounters the "log spiral" block in the scripting panel, it will take the value entered by the user in the text fields for the values of "C" (coilness), starting angle, ending angle, size, pen growth, and clockwise, executing those parameters of the curve in relationship to the original pen size, point in direction, and so on. Each of these values in the $\log$ spiral block is specific to the practices of Adinkra artisans. Yet, these ethnomathematics infused blocks must work smoothly and consistently with the rest of the system; otherwise we risk a profusion of special purpose blocks and imply that indigenous knowledge is in some sense an inverse of universal knowledge, only applicable to its own narrow context. Just as we want to encourage students to feel that they do not need to give up their cultural identity to become scientists or mathematicians, the coding blocks themselves must also simultaneously embody the local and the universal.

\section{Evaluation}

The Adinkra Computing CSDT was tested in a "quasi-experimental evaluation" (Cook, Campbell, \& Day, 1979) using control and intervention groups in a junior high school in Ghana. We refer to this as a "quasiexperiment" because as stated in the education evaluation literature, unlike a laboratory setting, researchers in a classroom cannot control every variable. Within those constraints the crucial variables were controlled: all students were from the same school, the same grades (a combination of 7th and 8th), with the lessons taught by the same teachers. To prevent unconscious bias, we assigned our student participants to either the control group or an experimental group using a random number table. We had two 
groups of 10 , with an attrition of $10 \%$ in the intervention group resulting in only 9 students.

We taught the mathematics of logarithmic spirals to the students in both groups using a similar format of lecture, followed by reinforcement of concepts taught with simulation software. We developed the control group lesson using a freely available website that details the mathematics of logarithmic spirals, followed by a GeoGebra based logarithmic spiral applet to reinforce the mathematics lesson based on the website. In addition, the control group lesson also included a teacher led guided practice using the GeoGebra software, as well as a group practice where students collaborated on a learning project. This allowed us to avoid confusion by having both groups use software and receive verbal lessons; the non-cultural software of GeoGebra served as the control for that pedagogical context.

The intervention lesson included the same mathematical concepts as those used with the control group; however, each of the concepts were motivated and taught using an Adinkra symbol. For example, in a review of the Cartesian plane (Figure 9), we used the "Kronti Ne Akwamu" (Figure 10), the symbol for "the dual nature of life and democratic decision making in the State of Ghana" (Willis, 1998). The symbol enabled a comparison between the positive and negative combinations across quadrants and the importance of disagreement $(-\mathrm{x}, \mathrm{y}$ and $\mathrm{x},-\mathrm{y})$ in democratic decisionmaking. This enabled us to expose the embedded mathematical structures present in the symbol to the students.

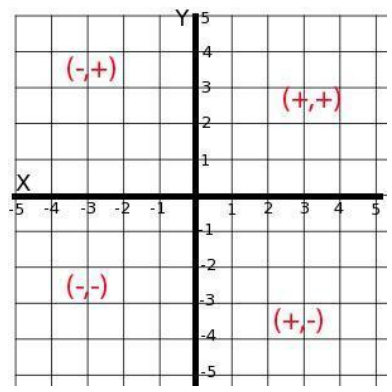

Figure 9. The Cartesian plane. 


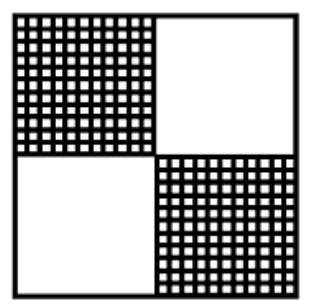

Figure 10. Kronti Ne Akwamu Adinkra symbol.

The intervention group lesson used the Adinkra Computing CSDT to reinforce the mathematics lesson based on the Adinkra symbols. Like the control group, the experimental group also included a teacher led guided practice and a group collaboration project.

The control group intervention occurred prior to the experimental group intervention. Both interventions began with a pretest and ended with a posttest that measured the students' knowledge of the topics covered in the lesson. The control group received two days of instruction using the lecture and GeoGebra software simulation. The experimental group received three days of instruction using lecture and Adinkra Computing in CSnap. The extra day in the experimental group intervention was included for students to explore the cultural significance of Adinkra. ${ }^{4}$ Instruction time on the math of logarithmic spirals was equal in both groups.

The pretest and posttests formed the independent samples for a t-test. The results showed a significant advantage for the scores for the Adinkra computing based lesson $(\mathrm{M}=45.22, \mathrm{SD}=18.67)$ in comparison to the GeoGebra computing based lesson $(\mathrm{M}=13.87, \mathrm{SD}=15.93)$; the difference was statistically significant at the .001 confidence level.

\section{Discussion}

The successful use of Adinkra symbols to support mathematics learning in this study can serve as encouragement to Ghanaian parents and teachers, as they seek to include local resources in math, science, and computing curricula. Adopting local resources to use in lesson plans that disrupt "traditional" methods of education can be a daunting task. Often the highest 


\section{Babbitt, Lachney, Bulley \& Eglash - Adinkra Mathematics}

barriers to overcome are those put in place by institutions, such as the Ministry of Education. These barriers usually come in the form of prescribed lesson plans, which are designed to yield specific student outcomes on standardized tests. Given these conditions we have considered two avenues for moving forward with integrating Adinkra in Ghanaian math, science, and computing curricula: 1) school communities and educators lobby the Ministry of Education to include Adinkra in curricula; 2) teachers who have the time and interest develop Adinkra lessons that meet curricular standards, to use in their own classrooms and share with others.

Both of these avenues require that the math, science, and computing aspects of Adinkra be popularized among community members and educators. One possible way to popularize lessons like Adinkra Computing is through forming relationships with Parent-Teacher Associations (PTAs). In our collaborations with Ghanaian schools, we have found that PTA members can act as a bridge between communities and educators. It is our goal that this study be used to support future documents written for PTA audiences, which explain how Adinkra can be used in classrooms across primary and secondary school curricula while also enhancing student performance.

Although we believe that the use of the Adinkra Computing CSDT to reinforce the learning in the intervention group was a success, we realize that there are limitations in this particular quasi-experiment. One possible limitation is that our sample size is small with only 19 student's total (10 students for the control group and 9 in the intervention group). This number however, was as large as possible, given the constraints placed on us by the number of computers available for student use. We wanted to make sure that each student had access to their own machine to limit the potential effects of students having to share equipment. The students used all available computing equipment in the classroom, including all teachermachines. This is a limitation of the study and its possible relevance to further classroom implementation, since it is more common for students in Ghana to work on computers in groups as opposed to individually.

One of the most exciting anecdotal outcomes of the experiment was the reaction of students in the intervention group. While control group students 
freely left the classroom not long after the lesson ended, the intervention group students were ready to reclaim their computers and form small groups at the front of the room to continue working with the Adinkra Computing software. This is not unique to Ghana; similar outcomes have been observed in the US for African American, Latino and Native American students; a promising sign for this approach.

\section{Conclusion}

This study has shown how ethnomathematics research can be used to develop ethnocomputing interventions in classrooms. The ethnocomputing activity, Adinkra Computing engaged students' interest and increased mathematical performance between pretests and posttests. In future research we hope to examine the role that heritage variation might play in these results. In this case, we carried out the testing in the Akan cultural region; thus, many of the students would likely have been of Akan extraction. While Adinkra symbols have taken on a national identity in Ghana, and even pan-African symbolism globally, there is still a sense of its close identification with Akan cultural heritage. Thus, we may see different results elsewhere in Ghana. We have seen a great deal of variation with CSDTs in the US, with some African American students expressing more interest in Native American design tools and vice-versa (Babbitt, Lyles \& Eglash, 2012). Data on Adinkra Computing across the different regions of Ghana will provide further understanding about how the math, science, and computing aspects of Adinkra symbols may be interpreted similarly or differently based on the geographical location and cultural context of implementation.

\section{Notes}

1. This research was made possible by NSF grant DGE-0947980 and conducted under IRB \#998.

2. http://www.csdt.rpi.edu 
3. It should be noted that this process is always partial: some of the traditional knowledge was lost in the colonial era, and even in the original context the deeper indigenous conceptions are often "networked" across a variety of practices - healers, farmers, artisans, and others as well as non-human elements of the ecosystems in which they were embedded.

4. During our ethnographic research, we found that while many of the JHS students we worked with were aware of the most culturally popular Adinkra symbols, they were not familiar with the history or current production practices that surround Adinkra. This makes our ongoing work on Adinkra math and computing with junior high school students in control and intervention groups, as well as the surrounding region, of critical importance for both cultural and ethical reasons.

\section{References}

Ahia, F., \& Fredua-Kwarteng, E. (2012). Gazing Mathematics and Science Education in Ghana. In A. Asabere-Ameyaw, G. J. Sefa Dei, K. Raheem, \& J. Anamuah-Mensah (Eds.), Contemporary Issues in African Sciences and Science Education (pp. 103-125). Rotterdam: Sense Publishers.

Anamuah-Mensah, J., Mereku, D., \& Asabere-Ameyaw, A. (2004).

Ghanaian junior secondary school students' achievement in mathematics and science: Results from Ghana's participation in the 2003 Trends in International Mathematics and Science Study. Accra: Ministry of Education Youth and Sports.

Anderson, S. (1990). Worldmath curriculum: Fighting Eurocentrism in mathematics. Journal of Negro Education, 348-359.

Ascher, M. (1994). Ethnomathematics: A Multicultural View of Mathematical Ideas. Boca Raton, FL: CRC Press.

Ascher, M., \& D'Ambrosio, U. (1994). Ethnomathematics: A dialogue. For the Learning of Mathematics, 14(2), 36-43.

Babbitt, B., Lyles, D., \& Eglash, R. (2012). From Ethnomathematics to Ethnocomputing. In S. Mukhopadhyay \& W.-M. Roth (Eds.), Alternative Forms of Knowing (in) Mathematics (pp. 205-219). Rotterdam: Sense Publishers.

Cobb, P., \& Hodge, L. L. (2002). A relational perspective on issues of cultural diversity and equity as they play out in the mathematics 
REMIE - Multidisciplinary Journal of Educational Research, 5(2) 129

classroom. Mathematical thinking and learning, 4(2-3), 249-284. doi:10.1207/S15327833MTL04023_7

Cook, T. A. (1979). The curves of life: being an account of spiral formations and their application to growth in nature, to science, and to art: with special reference to the manuscripts of Leonardo da Vinci. New York, NY: Dover Publications.

Cook, T. D., Campbell, D. T., \& Day, A. (1979). Quasi-experimentation: Design \& analysis issues for field settings. Boston, MA: Houghton Mifflin.

D'Ambrosio, U. (2010a). Ethnomathematics: A response to the changing role of mathematics in society. Philosophy of Mathematics Education, 25. Retrieved from http://people.exeter.ac.uk/PErnest/pome25/index.html

D'Ambrosio, U. (2010b). From Ea, through Pythagoras, to Avatar: Different settings for mathematics. Paper presented at the Proceeding of the 34th conference of the international group for the psychology of mathematics education.

Dei, G. J. S. (2004). Schooling and education in Africa: The case of Ghana: Africa World Press.

Eglash, R. (1999). African Fractals: Modern Computing and Indigenous Design. Piscataway, NJ: Rutgers University Press.

Eglash, R., \& Bennett, A. (2009). Teaching with Hidden Capital: Agency in Children' s Computational Explorations of Cornrow Hairstyles. Environments, 19(1), 58-73. Retrieved from http://www.colorado.edu/journals/cye

Eglash, R., Bennett, A., O Donnell, C., Jennings, S., \& Cintorino, M. (2006). Culturally situated design tools: Ethnocomputing from field site to classroom. American Anthropologist, 108, 347. doi:10.1525/aa.2006.108.2.347

Eglash, R., \& Garvey, C. (2014). Basins of Attraction for Generative Justice. In S. Banerjee, S. S. Ercetin, \& A. Tekin (Eds.), Chaos Theory in Politics (pp. 75-88). Netherlands: Springer.

Eglash, R., Krishnamoorthy, M., Sanchez, J., \& Woodbridge, A. (2011). Fractal simulations of African design in pre-college computing 
130 Babbitt, Lachney, Bulley \& Eglash - Adinkra Mathematics

education. ACM Transactions on Computing Education (TOCE), 11, 17. doi:10.1145/2037276.2037281

Elliott, F. (2009). Science, Metaphoric Meaning, and Indigenous

Knowledge. Alberta Journal of Educational Research, 55(3), 284297.

Ezeife, A. N. (2003). Using the environment in mathematics and science teaching: An African and aboriginal perspective. International Review of Education, 49(3-4), 319-342. doi:10.1023/A:1025307404154

Fordham, S. (1991). Peer-proofing academic competition among black adolescents: "Acting white" black American style. In C. E. Sleeter (Ed.), Empowerment through multicultural education (pp. 69-93). Albany, NY: State University of New York Press.

Frankenstein, M., \& Powell, A. B. (1994). Toward liberatory mathematics: Paulo Freire's epistemology and ethnomathematics. In C. Lankshear \& P. McLaren (Eds.), Politics of liberation: Paths from Freire (pp. 74-99). London, UK: Routledge.

Freire, P. (2000). Pedagogy of the oppressed. New York, NY: Bloomsbury Publishing.

Fryer Jr, R. G., \& Torelli, P. (2010). An empirical analysis of acting white. Journal of Public Economics, 94(5), 380-396.

doi:10.1016/j.jpubeco.2009.10.011

Gerdes, P. (1985). Conditions and strategies for emancipatory mathematics education in undeveloped countries. For the Learning of Mathematics, 5(1), 15-20.

Gutstein, E. (2006). Reading and writing the world with mathematics:

Toward a pedagogy for social justice. New York, NY: Routledge.

Harding, S. G. (2008). Sciences from below: Feminisms, postcolonialities, and modernities. Durham, NC: Duke University Press.

Jama, J. M. (1999). The role of ethnomathematics in mathematics education cases from the horn of Africa. ZDM, 31(3), 92-95.

doi:10.1007/BF02652730

Khan, S. (2011). Ethnomathematics as Mythopoetic Curriculum. For the Learning of Mathematics, 31(3), 14-18.

Lipka, J., Hogan, M. P., Webster, J. P., Yanez, E., Adams, B., Clark, S., \& Lacy, D. (2005). Math in a cultural context: Two case studies of a 
successful culturally based math project. Anthropology \& Education Quarterly, 36(4), 367-385. doi:10.1525/aeq.2005.36.4.367

Nasir, N. i. S. (2002). Identity, goals, and learning: Mathematics in cultural practice. Mathematical thinking and learning, 4(2-3), 213-247. doi:10.1207/S15327833MTL04023_6

Ogbu, J. U., \& Simons, H. D. (1998). Voluntary and involuntary minorities: a cultural-ecological theory of school performance with some implications for education. Anthropology \& Education Quarterly, 29(2), 155-188. doi:10.1207/S15327833MTL04023_6

Osei, G. M. (2006). Teachers in Ghana: issues of training, remuneration and effectiveness. International Journal of Educational Development, 26(1), 38-51. doi:10.1016/j.ijedudev.2005.07.015

Roth, W.-M., \& Barton, A. C. (2004). Rethinking scientific literacy. New York, NY: Routledge Falmer.

Steele, C. M., Spencer, S. J., \& Aronson, J. (2002). Contending with group image: The psychology of stereotype and social identity threat. Advances in experimental social psychology, 34, 379-440. doi:10.1016/S0065-2601(02)80009-0

West, G. B., Brown, J. H., \& Enquist, B. J. (1997). A general model for the origin of allometric scaling laws in biology. Science, 276(5309), 122126. PMID:9082983

Willis, W. B. (1998). The Adinkra dictionary: A visual primer on the language of Adinkra. Washington, DC: Pyramid Complex.

Zaslavsky, C. (1994). 'Africa Counts' and ethnomathematics. For the Learning of Mathematics, 14(2), 3-8. 
132 Babbitt, Lachney, Bulley \& Eglash - Adinkra Mathematics

William Babbitt is a recent graduate of the Multidisciplinary Sciences program at Rensselaer Polytechnic Institute in Troy, NY, USA.

Michael Lachney is a Ph.D. Candidate at Rensselaer Polytechnic Institute in Troy, NY, USA.

Enoch Bulley is an ICT teacher at the Ayeduase Junior High School in Kumasi Ghana.

Ron Eglash is Professor in the Science and Technology Studies Department at Rensselaer Polytechnic Institute in Troy, NY, USA.

Contact Address: William Babbitt. Rensselaer Polytechnic Institute 110 8th St, Troy, NY 12180, United States. Email: bill@wbabbitt.com 
REMIE - Multidisciplinary Journal of Educational Research, 5(2) 133

\section{Appendix A}

\section{Pre/Post Test}

1) Define the following terms in your own words. You may draw images to help you explain.
a) Exponential Growth
b) Exponential Parameter
c) Tangent Vector
d) Angle
e) Degree
f) Cartesian Plane

2) Describe how you would create the following figure using math or computing.

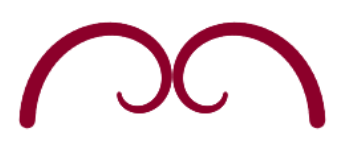

3) Name three examples of logarithmic spirals in nature.
a)
b)
c) 
134 Babbitt, Lachney, Bulley \& Eglash - Adinkra Mathematics

4) Look at spirals a, b, and c below. Put the spirals in order from the smallest to the largest exponential parameters. 1 being the smallest and 3 being the largest.

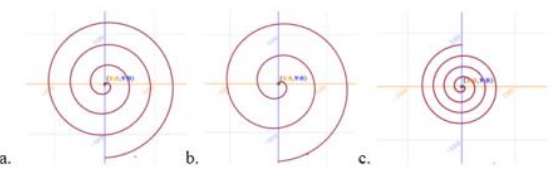

1. 2.

3.

a. b. c.

5) Describe the shape below mathematically.

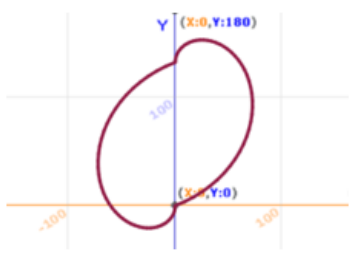

6) Give three examples of logarithmic spirals in everyday life.
a)
b)
c) 
REMIE - Multidisciplinary Journal of Educational Research, 5(2) 135

7) Look at shapes a and b, which shape is found more in nature? Circle the answer below.

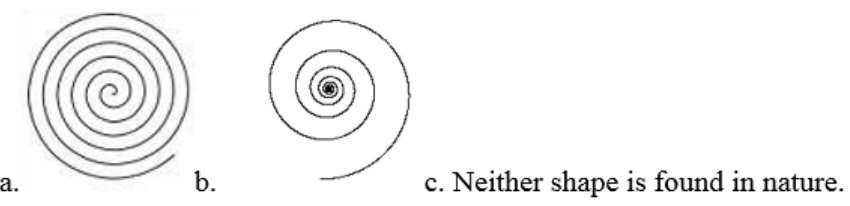

8) Draw two circles that intersect from the tangent vectors below.
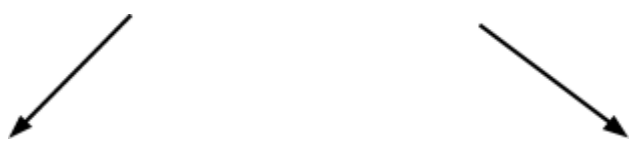